\title{
5 principios de la neuroeducación que la familia debería saber y poner en práctica
}

\author{
David Bueno *; Anna Forés **
}

Resumen. Durante estas dos últimas décadas, los estudios en neurociencia y neurociencia cognitiva han estado aportando datos muy interesantes sobre cómo se construye y aprende el cerebro. Aplicados a la educación, en lo que se viene en llamar neuroeducación, deben dejar de ser una disciplina estudiada solo en contextos neurocientíficos y pedagógicos para llegar a toda la sociedad, a todas aquellas personas interesadas en los aprendizajes de sus hijos e hijas y en los suyos propios. Este artículo pretende aproximar al lector los 5 principios básicos de la neuroeducación que deben conocer los padres y madres para llevarlos a la práctica y fomentar el aprendizaje y una vida más digna.

El trabajo se basa en estudios y escritos previos realizados por ambos autores desde la perspectiva más biológica y la perspectiva más educativa. Esta mirada transdisciplinar favorece romper ciertas fronteras de saberes cerrados para dar una visión más alineada con el funcionamiento integrado e integrador del cerebro.

Es importante que las familias y la sociedad en general, incluidos los organismos de toma de decisiones educativas, conozcan cómo podemos favorecer la educación de las nuevas generaciones a partir del conocimiento de cómo aprende el cerebro. Este artículo se enmarca en este objetivo de divulgación social.

Palabras clave: neuroeducación; neurodidáctica; cerebro.

\section{PRINCÍPIOS DA NEUROEDUCAÇÃO QUE A FAMÍLIA DEVERIA CONHECER E COLOCAR EM PRÁTICA}

Resumo. Durante as últimas duas décadas, os estudos em neurociência e neurociência cognitiva têm fornecido dados muito interessantes sobre como o cérebro é construído e como ele aprende. Tais estudos aplicados à educação, o que se chama de neuroeducação, devem deixar de ser uma disciplina estudada apenas em contextos neurocientíficos e pedagógicos para atingir toda a sociedade, todos aqueles interessados no aprendizado de seus filhos e filhas e no seu próprio. O objetivo deste artigo é aproximar o leitor dos cinco princípios básicos da neuroeducação que os pais e mães devem conhecer para colocá-los em prática e promover o aprendizado e uma vida mais digna.

O trabalho baseia-se em estudos anteriores e textos escritos por ambos os autores a partir da perspectiva mais biológica e da perspectiva mais

Barcelona, España

*Sección de Genética Biomédica, Evolutiva y del Desarrollo, Universidad de

${ }^{* *}$ Departamento de Didáctica y Organización Educativa, Universidad de Barcelona, España. 
educacional. Esta abordagem transdisciplinar favorece a quebra de certas fronteiras de saberes fechados para dar uma visão mais alinhada com o funcionamento integrado e integrador do cérebro.

É importante que as famílias e a sociedade em geral, incluindo os órgãos responsáveis pela tomada de decisão educacional, saibam como podemos promover a educação das novas gerações com base no conhecimento de como o cérebro aprende. Este artigo enquadra-se nesse objetivo de divulgação social.

Palavras-chave: neuroeducação; neurodidática; cérebro

\section{PRINCIPLES OF NEUROEDUCATION THAT FAMILIES SHOULD KNOW TO PUT INTO PRACTICE}

Abstract. During last two decades, research in neuroscience and cognitive neuroscience have provided significant data on how the brain builds and on the neuronal mechanisms of learning. Applied to education, in the socalled neuroeducation, it should stop being a discipline studied only in neuroscientific and pedagogical contexts to reach the whole society, all those people interested in the educational and learning processes of both their sons and daughters as well as in their own learning. This paper aims to bring the readers closer to the Five basic principles of neuroeducation that parents must know to put them into practice, to encourage learning and a more dignified life.

This paper is based on previous studies and writings made by both authors, from both the biological as well as educational perspectives. This transdisciplinary approach favors the breaking of certain frontiers between traditionally self-contained knowledges to give an integrated vision which is much closer to the integrated and integrating operativity of the brain.

It is important that families and society in general, including educational policy-making authorities, know how we can promote the education of new generations based on the knowledge of how the brain forms and learns. This article is part of this objective of social disclosure.

Keywords: neuroeducaction; neurodidactics; brain

\section{INTRODUCCIÓN}

Los avances sobre neuroeducación y neurodidáctica cada vez son más presentes en la academia. Autores como Francisco Mora, José Antonio Marina, Ignacio Morgado, Eric Kandel, Judy Willis, Paul Howard-Jones, Eric Jensen, Charo Rueda, Tomás Ortiz, José Ramón Alonso, Uta Frith, SarahJayne Blakemore, Rosa Casafont, Marta Ligioiz, José Ramón Gamo, Chema Lázaro y Jesús C. Guillén, entre otros, incluidos los autores de este artículo, en los últimos 10 años han publicado abundantes trabajos Ilevando estos avances a la sociedad. Pero la sociedad en general, y el colectivo de madres y padres en particular, pueden andar infotoxicados por la gran cantidad de informaciones vertidas, algunas al menos en apariencia contradictorias. Como 
cualquier concepto que se pone de moda, a las evidencias científicas se les unen informaciones falsas, neuromitos (Forés y col., 2015) y sentencias o propuestas poco firmes desde el punto de vista científico. Este artículo pretende acercar los conceptos básicos de la neurodidáctica, desde la mirada biológica y pedagógica, para que las madres y padres, y por extensión cualquier persona interesada en el tema, tengan evidencias y un saber básico para hacer de resorte de sus hijos en estas temáticas. Es importante conocer como aprendemos, saber cómo funciona nuestro cerebro para aprender más y mejor. Ya son muchos los estudios, que demuestran la importancia y la incidencia en el aprendizaje del conocimiento de cómo aprendemos, el poder de la metacognición (Diamond y Ling, 2016).

\section{LOS 5 PRINCIPIOS BÁSICOS DE LA NEUROEDUCACIÓN}

Muchos pueden ser los principios de la neuroeducación que deberíamos conocer para aplicar a nuestra vida cotidiana, de entre todos ellos hemos escogido estos cinco por su relevancia e impacto no sólo en educación sino en la vida.

\section{Principio 1. Somos seres únicos e irrepetibles. Superpoderes y responsabilidades}

El cerebro es el órgano más complejo de nuestro cuerpo. Dirige toda su actividad y marca nuestros patrones de comportamiento. Gracias a él no solo respiramos, comemos y nos movemos; también recordamos el pasado y planificamos el futuro, y en base a estos dos parámetros establecemos nuestro presente. ¿O tal vez sea al revés, y recordamos el pasado y planificamos el futuro en función de cómo percibimos y actuamos en cada momento de nuestro presente? Sea como fuere, no es poca cosa. Cuando amamos, odiamos, discutimos, cuidamos y olvidamos, todo se gesta en nuestro cerebro, en la actividad de sus 86.000 millones de neuronas. Aunque, de hecho, lo más importante no es este número, que puede variar entre dos personas cualesquiera, sino las conexiones que se establecen entre las neuronas, más de doscientos billones en cada cerebro. Porque tener 5.0000 10.000 millones de neuronas más o menos a partir de esa media no confiere ninguna capacidad extraordinaria ni implica ningún déficit significativo. En cambio, incrementar el número de conexiones, lo que se produce a través de las experiencias diarias, incluidos los procesos educativos, sí proporciona una mayor plasticidad neuronal y reserva cognitiva. Tal complejidad hace que cada cerebro sea único e irrepetible, y por consiguiente que cada mente sea un universo en sí misma. Esto implica que cualquier experiencia y todo proceso educativo influyan o puedan influir de manera ligeramente distinta en 
cada persona, según sea su cerebro. En un proceso retroalimentado, puesto que estas mismas experiencias también contribuyen a que cada cerebro sea único. Por eso cada hijo es diferente, único y singular.

Pero no es solo irrepetible si lo comparamos con otros cerebros, sino incluso si lo hacemos consigo mismo, puesto que cada día termina siendo ligeramente diferente a cómo era el día anterior. Nuestro cerebro, como el de nuestros hijos, cambia sin cesar. Sus conexiones van cambiando, influenciadas por las experiencias diarias, por todo aquello que aprendemos y por el simple contacto con el entorno, especialmente con el entorno social. Llevado al terreno de la paternidad, todo lo que los padres y las madres ofrecemos a nuestros hijos, desde la más sutil de las miradas hasta las cosquillas más alocadas, o desde el juego más divertido a la conversación más profunda, influye en cómo se construye y se reconstruye su cerebro, en cómo va a ser su mente. Sin embargo, ¿cuándo empezamos a influir sobre el cerebro de nuestros hijos? ¿Cuándo nacen? ¿Cuándo empiezan a tener uso de razón? ¿O tal vez antes, durante las semanas finales de la gestación? Sea como fuere (vamos a hablar de ello a continuación), esta influencia no sólo contribuye a establecer su presente, sino muy especialmente su futuro. Cómo suelen decir los superhéroes de las novelas gráficas, "un gran poder conlleva una gran responsabilidad". La responsabilidad de ser padres para con el cerebro de nuestros hijos. Esta es la historia de su cerebro (cómo también ha sido y continúa siendo la del nuestro).

\section{Principio 2. Influenciar no significa determinar}

Para sorpresa de muchos, la influencia de los progenitores sobre la construcción del cerebro de sus descendientes empieza antes de concebirlos, durante su propia adolescencia y juventud, cuando muy probablemente ni tan siquiera se han planteado si de mayores van a querer ser padres. El estilo de vida de los futuros madres y padres, especialmente durante la adolescencia y primera juventud, puede propiciar cambios en el epigenoma de sus células sexuales, los óvulos y los espermatozoides (Bueno, 2018). Y algunos de estos cambios pueden influir en aspectos concretos de la construcción del cerebro de sus futuros hijos e hijas, y por lo tanto pueden quedar reflejados en sus mentes.

El epigenoma consiste en la adición de determinadas moléculas al ADN que no alteran el mensaje que contiene (no son, por lo tanto, mutaciones), pero que contribuyen a regular la manera cómo funcionan algunos genes. Algunas de estas modificaciones epigenéticas, como se las Ilama, vienen genéticamente programadas y a menudo se producen de manera diferente en función del sexo de cada persona, pero muchas de ellas dependen de la interacción del genoma con el ambiente. Por ejemplo, se ha visto que en los 
adolescentes que consumen sustancias tóxicas, como marihuana o alcohol, el epigenoma de sus células sexuales incorpora determinadas modificaciones epigenéticas que influirán negativamente en la construcción del cerebro de sus futuros descendientes, a parte de influir también en el funcionamiento del suyo propio.

Los genes, y las modificaciones epigenéticas, son ciertamente importantes para la construcción del cerebro, pero no lo son todo, ni mucho menos. El genoma humano, es decir, el conjunto de su material hereditario, está formado por algo más de 20.000 genes, de los que unos 8.000 funcionan, en un momento u otro de la vida, en el cerebro, ya sea para construirlo, gestionar su consumo energético, comunicar las neuronas entre ellas, y un largo etcétera de otras funciones. Todo el mundo tiene estos genes, todos, pero no necesariamente las mismas variantes génicas. Según las variantes que hayamos pasado a nuestros hijos, su cerebro tendrá, de origen, unas características determinadas que influirán en todos sus aspectos mentales, como por ejemplo en su sociabilidad, inteligencia, creatividad, oído musical, capacidad artística, control muscular, etcétera.

Aquí la palabra clave, sin embargo, es "influenciar", no "determinar".

Porque en la construcción cerebral, los genes son solo la punta del iceberg. Se ha visto, por ejemplo, que hay genes que condicionen, no determinan, el coeficiente de inteligencia, la sociabilidad, e incluso el grado de empatía o de creatividad de cada persona. El cerebro se forma partiendo de este material biológico ineludible, que condiciona la mente que va a surgir de su funcionamiento, pero lo hace en constante interacción sinérgica con el ambiente, e incluso a través de los azares e imponderables con que a menudo la vida nos sorprende. Un ambiente entendido en sentido amplio, que incluye todos los aspectos familiares, sociales y educativos. Así, una persona que tiene buena predisposición genética hacia, pongamos por ejemplo, la creatividad musical, pero que la vea mutilada familiar, social o educativamente, terminará manifestando un grado mucho más bajo de esta característica que otra persona que, con menos predisposición genética, se vea agradablemente estimulada.

\section{Principio 3. Antes de nacer, preparamos el cerebro}

El primer síntoma de que el embrión se prepara para formar el cerebro lo vemos, curiosamente, en su "piel" -un tejido embrionario que en propiedad se denomina ectodermo-, unos dieciocho días después de la fecundación, aunque tardará diversos meses en convertirse en un cerebro funcional. Un grupito de células que hasta ese momento recubrían el embrión empieza a cambiar de forma y se pliegan formando un surco, que se irá cerrando hasta formar el denominado tubo neural, que recorre el embrión a todo lo largo. 
Poco después, la parte anterior de este tubo, que se sitúa en lo que terminará siendo la cabeza, se empieza a ensanchar. Este ensanchamiento se irá rellenado de capas de células, y constituirá el cerebro. El resto mantendrá la forma cilíndrica y terminará formando la medula espinal (Bueno, 2016).

Poco a poco, muchas de estas células se van convirtiendo en neuronas, y a partir de ese momento empiezan a establecer conexiones entre ellas.

Las células GLIA (unos 60.000 millones), que acompañan a las neuronas (16.000 millones en la corteza cerebral), son las encargadas de alimentarlas, limpiar el cerebro de las sustancias de desecho, evitar inflamaciones e impedir cortocircuitos, entre otras muchas funciones.

Algunas neuronas se conectan con "solo" una docena o unas pocas docenas de otras neuronas, pero se sabe que algunas Ilegan a conectarse hasta con otras diez mil neuronas más. Algunas de estas conexiones son locales y se restringen a las neuronas vecinas, de pocas milésimas de milímetro, mientras que otras cruzan distancias relativamente largas en el cerebro, de hasta algunos centímetros. Lo hacen espoleadas por sus programas génicos, que les indican cuando deben empezar a buscar a quien conectarse y qué dirección aproximada deben tener sus conexiones. Pero no les indican con qué otras neuronas concretas van a terminar conectadas, ni si sus conexiones van a ser muy numerosas o no. Esto depende en gran medida de la interacción con el ambiente, es decir, de los estímulos que reciba el cerebro en construcción.

La primera actividad neural, las primeras señales fehacientes de que las neuronas se están comunicando entre ellas de forma regular, se produce durante la semana 25 de gestación (aproximadamente a los cinco meses y medio), y ya no se va a detener jamás. En todo este período, y hasta el nacimiento, el estilo de vida de la madre, e incluso la atención y las muestras de afecto que le dedique su pareja, contribuirán a la formación del cerebro de su hijo.

Por ejemplo, se ha demostrado que las madres que practican deporte moderado durante el embarazo, sus hijos tienden a hacer más deporte en la adolescencia y de adultos, por la forma como la actividad materna influye en la construcción del cerebro fetal. Por la contra, madres fumadoras durante el embarazo incrementan hasta el 78\% las probabilidades de que su hijo pueda terminar sufriendo un trastorno mental, puesto que las sustancias tóxicas del tabaco dificultan el crecimiento del cerebro y su conectividad funcional. También se ha demostrado que las muestras de afecto hacia las personas gestantes producen una liberación incrementada de la hormona oxitocina 
que facilita la formación de conexiones neurales en el cerebro fetal en las zonas encargadas de gestionar las emociones, lo que redundará en beneficio de sus hijos e hijas.

\section{Principio 4. Después de nacer, más y más conexiones}

Tras el nacimiento, el cerebro continúa formándose. Nacemos con aproximadamente la mitad de neuronas que tendrá el cerebro adulto, por lo que inicialmente se deben formar muchas neuronas nuevas. Sin embargo, sobre los tres a cuatro años de edad, el cerebro ya contiene prácticamente todas las neuronas que precisa, y pocas más se añadirán en el transcurso de la vida. Pero a pesar de ello, su formación jamás está concluida, y continúa construyéndose y reconstruyéndose a lo largo de toda la vida. ¿Cómo se explica que se vaya construyendo y reconstruyendo constantemente, si prácticamente no incorpora neuronas nuevas?

Muy sencillo: lo hace estableciendo nuevas conexiones, que en terminología científica se denominan sinapsis. Este fenómeno, que es crucial para comprender nuestras características mentales y entender cómo van cambiando, se denomina plasticidad neural. Consiste, precisamente, en la capacidad que tienen las neuronas para establecer conexiones nuevas, y también para eliminar, en algunas ocasiones, las que están en desuso -un proceso que se denomina podado sináptico, por homología al podado de las ramas de los árboles-. El secreto de la vida mental y de las capacidades psíquicas se encuentra precisamente en estos patrones de conexiones neurales, en las redes neurales que conforman el cerebro.

La plasticidad neural es crucial en cualquier proceso de aprendizaje. $Y$ un recién nacido debe aprenderlo casi todo. Todo aquello que aprendemos, todo lo que recordamos, e incluso lo que no recordamos conscientemente pero que no obstante influye en nuestros comportamientos -a menudo más que las cosas que recordaos conscientemente-, se mantiene en nuestro cerebro implantado en unos patrones concretos de conexiones. Si el cerebro humano no pudiese hacer conexiones nuevas, llegado ese momento no podríamos aprender nada nuevo, solo usar lo que ya supiésemos con anterioridad. Por eso cada día, cuando nos acostamos, nuestro cerebro es necesariamente diferente a cómo era por la mañana al despertarnos, porque no pasa ni un solo día sin que aprendamos algo nuevo o sin que hayamos vivido alguna experiencia que merezca la pena ser recordada, al menos durante algún tiempo. Y las niñas y los niños son unas auténticas esponjas de asimilar novedades. De hecho, la característica más importante del cerebro durante la niñez es ser una esponja capaz de absorber en sus conexiones todo el ambiente que le rodea, para conocerlo y adaptarse a él. El cerebro infantil cambia constantemente, y en buena parte lo hace influenciado por el ambiente que les 
generamos y las experiencias que les proporcionamos. La estimulación -que no la sobreestimulación- es un elemento crucial para la formación del cerebro. Un cerebro estimulado va a tener más conexiones que el mismo cerebro sin esa estimulación, lo que implica más capacidad para organizar la vida mental y más reserva cognitiva para el resto de su vida.

Texto a parte:

- El enemigo número de nuestro cerebro es el estrés, concretamente el estrés crónico. Y solo se le puede hacer frente con placer y motivación. La estimulación da respuesta a nuestra curiosidad, pro la sobreestimulación nos satura y nos estresa, y empezamos a generar cortisol.

- El $8 \%$ de los niños y el $20 \%$ de los adolescentes tienen estrés crónico

- Chicos y chicas entre 9 y 24 años sometidos a estrés crónico agudo, tienen alteraciones permanentes en las conexiones neurales, especialmente en las amígdalas (las regiones del cerebro encargadas de generar las emociones), y eso hace que cuando sean más mayores tengan dificultades para gestionar las emociones negativas tendiendo más a reacciones agresivas, y tengan menor autoestima y autoconfianza.

\section{Principio 5. Ventanas de oportunidad: Las tres grandes etapas}

El cerebro de nuestros hijos es una esponja que absorbe todo lo que le rodea, por un motivo muy simple, relacionado con las funciones de este órgano rector. Como ya se ha dicho, la función cerebral dirige y armoniza todas nuestras actividades corporales, y genera nuestra actividad mental. Esta actividad incluye, por supuesto, todos los aspectos relativos al comportamiento. Pues bien, el cerebro es el órgano que permite que adaptemos y readaptemos nuestro comportamiento al ambiente en el cual nos formamos y nos encontramos, para cumplir con la función biológica más elemental -y crucial- de todas: sobrevivir. Adaptarse para sobrevivir, esta es la máxima de la biología. También, o muy especialmente, a través del comportamiento. La infancia que damos a nuestros hijos influirá de manera decisiva su carácter y el comportamiento que manifestarán cuando sean adultos. Como se ha citado al inicio del artículo en relación a los superhéroes de las novelas gráficas, "un gran poder conlleva una gran responsabilidad".

Dicho de otro modo, el ambiente que proporcionemos a nuestros hijos, entendiéndolo en sentido amplio -familiar, social y educativo-, contribuirá a la forma física que tomarán sus conexiones cerebrales, lo que se 
traducirá no solo en conocimientos sino también, muy especialmente, en todos los aspectos de su comportamiento, que se adaptará a ese entorno. Sin embargo, de forma programada por los genes no se potencian las mismas conexiones a una edad que a otra.

En general se distinguen tres grandes etapas desde el nacimiento hasta alcanzar la edad adulta (Figura 1), como han distinguido diversos autores (Mora, 2013; Bueno, 2017).

\section{(1) TRES ETAPAS, IDEAS Y
PROPUESTAS}



Etapa esencial para imprimir el carácter y temperamento. Es muy importante ofrecer un feedback de todo lo que va aprendiendo del mundo y de la percepción de sus experiencias. Es de vital importancia el vínculo seguro con sus progenitores o sus cuidadores.
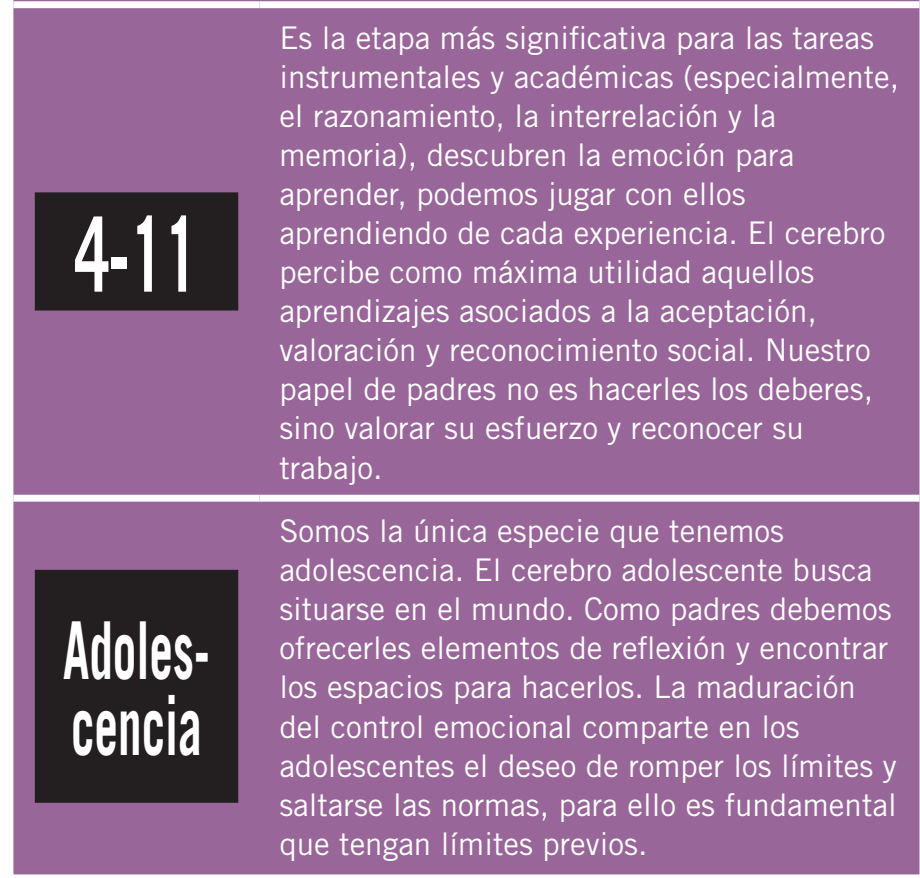

Figura 1. Resumen de las tres grandes etapas de desarrollo cerebral tras el nacimiento. Autoría propia 


\section{De los 0 a los 3 años}

De los 0 a los 3 años, el cerebro prioriza las conexiones entre neuronas cercanas en la denominada corteza cerebral. La corteza constituye la capa más externa del cerebro, y es donde se generan y gestionan los aspectos más complejos y típicamente humanos del comportamiento: el lenguaje, la toma de decisiones, el control ejecutivo, la empatía, el raciocinio y el control emocional, entre otros. A estas edades el cerebro absorbe el ambiente para adaptarse a él, lo que hace que sea la etapa más importante e influyente para la personalidad que mostraran nuestros hijos cuando sean adultos. Formarse en un ambiente de alta conflictividad, por ejemplo, estimula conexiones neurales que favorecen una alta impulsividad, como forma de respuesta a las posibles amenazas, lo que redunda en contra de la reflexividad (como característica mental opuesta).

\section{De los 4 a los 11 años}

En esta segunda etapa se favorecen las conexiones de media distancia, entre la corteza cerebral y algunas zonas internas del cerebro, cómo las denominadas amígdalas, que generan las emociones, y el hipocampo, que es el centro gestor de la memoria. A este respecto cabe decir, sin embargo, que la memoria no reside en el hipocampo, sino en redes neurales y en patrones de conexiones distribuidos por todo el cerebro. El hipocampo vendría a ser como la lista de preferidos de un buscador de internet: contiene las direcciones de las redes donde se almacena la información para recuperarla cuando sea menester, pero no la información per se. El hecho de que hasta los 3 o 4 años no se empiecen a formar conexiones entre la corteza y el hipocampo explica por qué casi nadie recuerda de forma consciente las experiencias anteriores a los 3 años de edad -lo que no quita que estas experiencias sean las más influyentes para la vida adulta, como ya se ha dicho-.

Es la etapa que más influye en las destrezas académicas -en las denominadas competencias básicas-. Es cuando las niñas y los niños aprender a leer, a escribir, los primeros razonamientos lógico-matemáticos, estrategias de memorización, etcétera. Cabe decir, sin embargo, que cada cerebro va madurando a un ritmo ligeramente diferente a los demás, lo que implica que la edad de aprender estas destrezas sea un poco variable. Esto implica que si queremos sacar el máximo provecho al desarrollo del cerebro, se deben respetar los ritmos individuales, para evitar el aburrimiento en las personas que madura más rápidamente y generar estrés en las que madura con más lentitud. 


\section{La adolescencia}

Finalmente, la adolescencia es la etapa en que el cerebro y sus programas génicos priorizan las conexiones a más larga distancia, lo que se relaciona con la gran capacidad de aprender cosas nuevas de forma consciente que se manifiesta a estas edades. En este sentido, cuantas más conexiones soporten un aprendizaje o un recuerdo, y muy especialmente si además contienen componentes emocionales (conexiones con las amígdalas) y sociales, y cuanto más extensas sean las redes neurales implicadas, mejor se recordará ese aprendizaje o experiencia y con más eficiencia se podrá utilizar en el futuro. Dicho de otro modo, y esto sirve para todas las etapas de desarrollo cerebral, para que un aprendizaje se enraíce bien en las conexiones cerebrales debe contener elementos emocionales y sociales, y debe encontrarse en un contexto cercano a las personas que lo reciben, para potenciar al máximo estas redes neurales. En paralelo, el establecimiento de estas conexiones permite que poco a poco, muy lentamente, vayan madurando capacidades tan importantes como la capacidad de tomar decisiones, el control emocional, la capacidad de retrasar las recompensas, la lógica y el raciocinio, etcétera.

El establecimiento de estas conexiones también se relaciona con la curiosidad y la búsqueda de novedades típicos de este período vital, que a menudo se traducen en, o los interpretamos como, rebeldía. Y lo que tal vez sea más importante. Una de las mejores formas que tiene el cerebro de adquirir nuevos conocimientos, especialmente los sociales, y estimular su plasticidad, es por imitación. Se decía justo al inicio del artículo que gracias a la actividad cerebral recordamos el pasado y planificamos el futuro, y en base a estos dos parámetros establecemos nuestro presente. Y se preguntaba retóricamente que a lo mejor es al revés, y que recordamos el pasado y planificamos el futuro en función de cómo percibimos y actuamos en cada momento de nuestro presente. Nuestros hijos e hijas viven su presente imitando lo que ven a su alrededor, incluyéndonos a nosotros, nuestras actitudes y comportamientos -aunque no siempre sea evidente-. Y con esta imitación aprenden a vivir su propia vida, una vida que sin duda les llevará al futuro. Esta es la historia de su cerebro, que empieza en nosotros pero que va mucho más allá, hacia su futuro.

\section{CONCLUSIONES}

En este artículo hemos pretendido hacer un Ilamamiento al empoderamiento de los padres y de la sociedad en general, incluidos los gestores de políticas educativas, hacia la educación de las nuevas generaciones a partir de la aplicación de los nuevos avances en neurociencia y neurociencia cognitiva en el campo de la educación y la pedagogía. La neuroeducación 
se está postulando como una herramienta muy potente para mejorar las estrategias educativas y contribuir a dignificar la vida humana, proporcionando datos y evidencias científicas a la pedagogía para que profundice en sus propuestas. Estos 5 principios constituyen los elementos básicos sobre los que se va construyendo esta nueva educación.

Somos seres únicos e irrepetibles eso lo hemos visto y además con "superpoderes" y responsabilidades. Por tanto debemos atender la diversidad y respetar los ritmos de aprendizaje de cada chico o chica. Saber dotar a cada uno de ellos de lo que va necesitando según su proceso evolutivo. Somos responsables de todo nuestro potencial y de su relevancia para nuestra descendencia.

Influenciar no significa determinar, sentirse responsable como progenitores pero también sabiendo del poder del contexto de aprendizaje que facilitemos a los más pequeños es altamente significativo también. Tenemos mucho por aportar y por decidir, a nivel familiar, pero también a nivel escolar y de políticas educativas.

Antes de nacer, preparamos el cerebro. Es necesario saber de la incidencia de las decisiones de los adolescentes y jóvenes y su relevancia para 24 los futuros hijos. Se debe formar a los adolescentes, en el funcionamiento del cerebro y que conozcan realmente como se aprende y la incidencia de sus decisiones en la vida.

Después de nacer, más y más conexiones. Propiciar experiencias de aprendizaje, entornos, emociones que hagan las conexiones neuronales más fuertes y de mayor volumen y calidad también requiere de nuestra atención y aportación. Escuelas emocionantes, vivencias de aprendizaje en familia, contextos ricos de retos y desafíos.

Ventanas de oportunidad: conocer las tres grandes etapas, y poder entender que está pasando y en que podemos ayudar, es básico como adultos referentes. Maestros, padres y madres y toda la comunidad educativa debería no sólo tener información sobre las ventanas de oportunidad sino también de cómo potenciar sus beneficios en la escuela y en casa.

Evidentemente los 5 principios no recogen toda la labor por hacer en este terreno pero si un inicio del trabajo pendiente que ya empieza a ser ineludible, y la familia es clave, de ahí este artículo dedicado a ella. 


\section{BIBLIOGRAFÍA}

Alonso, J.R., I. Alonso Esquisábel (2018). Colección Neurociencia y Psicología, El País. Madrid.

Blakemore, S.-J. y Frith, U. (2011). Cómo aprende el cerebro: las claves para la educación. Ariel.

Bueno, D. (2016). Cerebroflexia. El arte de construir el cerebro. Barcelona: Plataforma Editorial.

Bueno, D. (2017). Neurociencia para educadores. Barcelona: Octaedro.

Bueno, D. (2018). Epigenoma, para cuidar tu cuerpo y tu vida. Barcelona: Plataforma Editorial.

Casafont, R. (2014). Viaje a tu cerebro emocional. Ediciones B, S.A. Edición digital.

Codina Felip, M. J. (2015). Neuroeducación en virtudes cordiales. Cómo reconciliar lo que decimos con lo que hacemos. Barcelona: Octaedro.

Diamond A., Ling D. S. (2016). Conclusions about interventions, programs, and approaches for improving executive functions that appear justified and those that, despite much hype, do not. Developmental Cognitive Neuroscience 18, 34-48.

Forés A., y Ligioiz M. (2009). Descubrir la neurodidáctica: aprender desde, en y para la vida. Barcelona: UOC.

Forés A., Gamo, J.R., Guillén J.C., Hernández T., Ligioiz M., Pardo F. y Trinidad C. (2015). Neuromitos en educación. Barcelona: Plataforma Editorial.

Guillén J. C. (2017). Neuroeducación en el aula: de la teoría a la práctica. UK: CreateSpace.

Howard-Jones, P. (2011). Investigación neuroeducativa. Madrid: La Muralla.

Jensen, E. y Snider, C. (2013). Turnaround tools for the teenage brain. Jossey-Bass.

Kandel, E. (2007). En busca de la memoria: el nacimiento de una nueva ciencia de la mente. Katz.

Marina, J. A. (2011). El cerebro infantil: la gran oportunidad. Ariel.

Mora, F. (2013). Neuroeducación: sólo se puede aprender aquello que se ama. Madrid: Alianza Editorial.

Morgado, I. (2014). Aprender, recordar y olvidar. Claves cerebrales de la memoria y la educación. Ariel.

Ortiz, T. (2009). Neurociencia y educación. Madrid: Alianza Edtorial.

Rueda M. R. et al. (2016): Neurociencia cognitiva del desarrollo. En Mente y cerebro: de la psicología experimental a la neurociencia cognitiva. Madrid: Alianza Editorial.

Willis, J. (2008). How your child learns best: brain-friendly strategies you can use to ignite your child's learning and increase school success. Sourcebooks. 